\title{
Successful treatment with anti-tumor necrosis factor alpha for reactive small-bowel amyloidosis
}

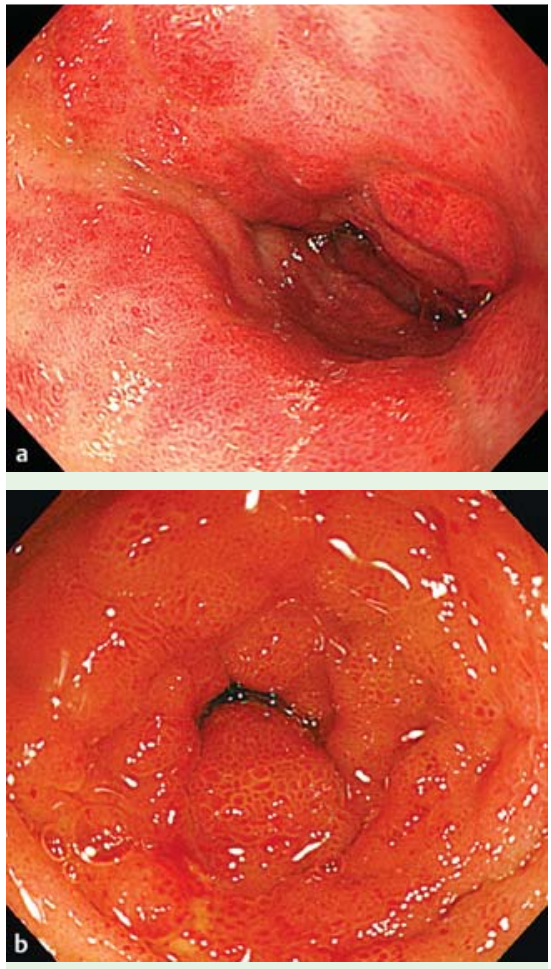

Fig. 1 Marked submucosal edema and multiple hemorrhagic erosions were seen in: a the deep part of the duodenum at esophagogastroduodenoscopy; and $\mathbf{b}$ the ileum at singleballoon enteroscopy.

A 62-year-old woman who was taking naproxen, methotrexate, and leflunomide for treatment of long-standing, poorly controlled rheumatoid arthritis was admitted because of a 4-week history of watery diarrhea and abdominal pain. Laboratory studies revealed the following results: leukocytes $16.5 \times 10^{9} / \mathrm{L}$, hemoglobin $9.8 \mathrm{~g} / \mathrm{dL}$, platelets $899 \times 10^{9} / \mathrm{L}$, total protein $62 \mathrm{~g} / \mathrm{L}$, albumin $29 \mathrm{~g} / \mathrm{L}$, and C-reactive protein $334 \mathrm{mg} / \mathrm{L}$. Tests of renal function were normal. On the second hospital day, she developed fever and received broad-spectrum antibiotics, but she deteriorated clinically over the next three days. Multiple stool tests gave negative results for bacterial infection. Endoscopic examinations showed marked submucosal edema and hemorrhagic erosions in the deep part of the duodenum and ileum $(\bullet$ Fig. 1a), and multiple biopsy specimens revealed amyloid $A(A A)$ protein deposition. A diagnosis of small-bowel AA

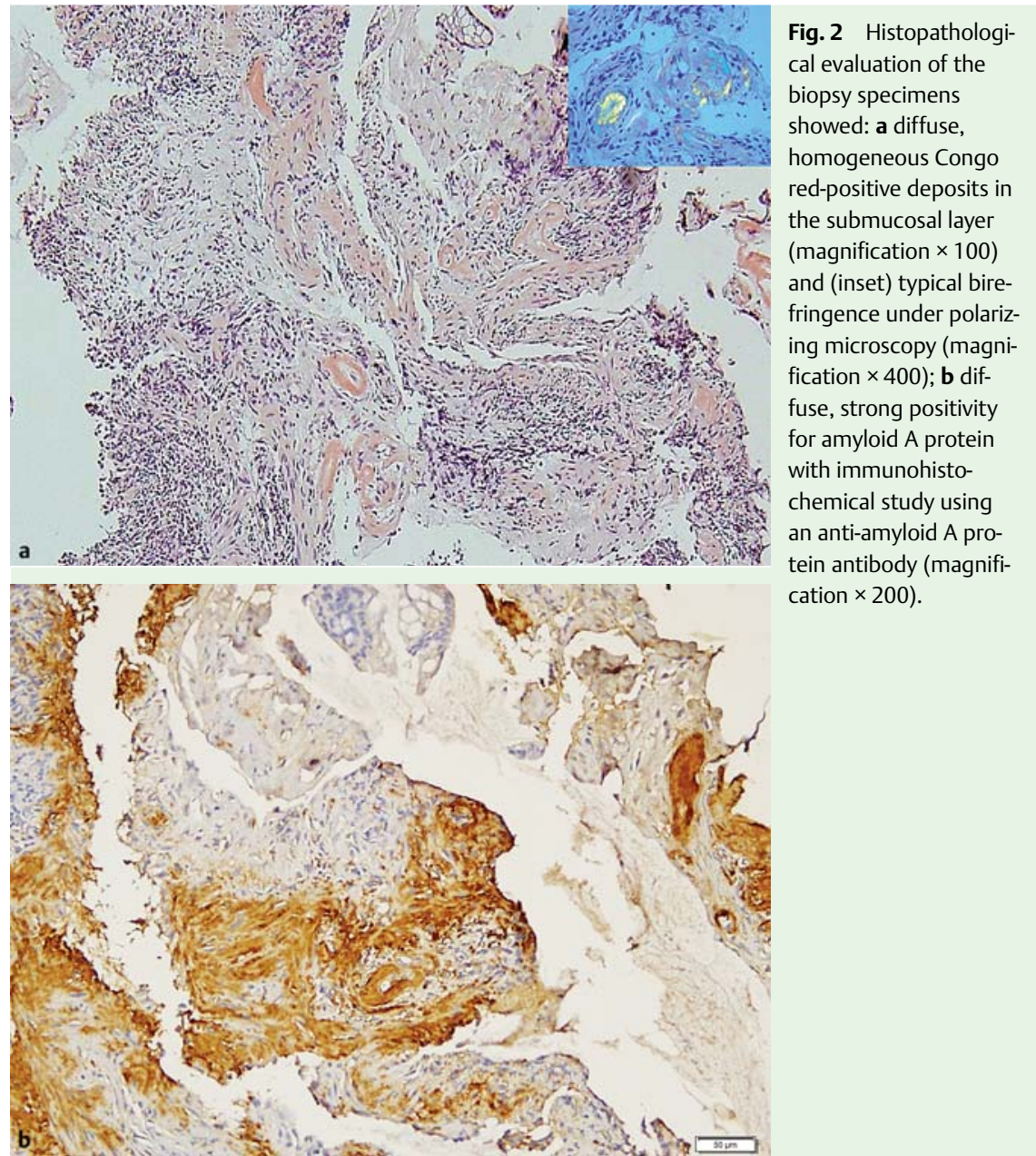

amyloidosis associated with rheumatoid arthritis was made ( $\bullet$ Fig. 2).

She was treated with anti-tumor necrosis factor- $\alpha$ (TNF- $\alpha$ ) antibody (infliximab, $5 \mathrm{mg} / \mathrm{kg}$ ) at weeks 0,2 , and 6 . After the first dose of infliximab, results for the acute-phase reactants immediately normalized, and her symptoms largely resolved within 3 days. A follow-up endoscopy 8 weeks after treatment showed complete resolution of the intestinal lesions ( Fig. 3), and the amyloid deposition had disappeared in the serial biopsy specimens. The patient has remained well without recurrence of her gastrointestinal symptoms during 12 months of follow-up.

Reactive amyloidosis is a critical complication with poor prognosis in patients with chronic inflammatory diseases, and usually affects the kidney [1-4]. We present herein a case of reactive small-bowel amyloidosis complicating rheumatoid arthritis, which was successfully treated with a novel therapeutic agent, anti-TNF$\alpha$ antibody. This case highlights the fact that early comprehensive endoscopy and multiple endoscopic biopsies, especially for small-bowel disease, are important for immediate diagnosis and treatment in patients with rheumatoid arthritis and persistent gastrointestinal symptoms.

Endoscopy_UCTN_Code_CCL_1AC_2AH

Competing interests: None 


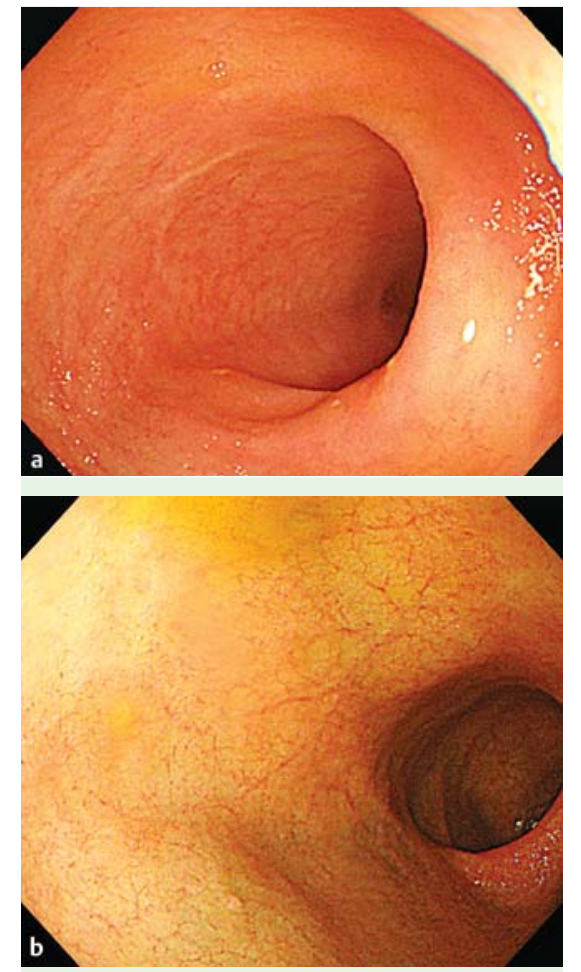

Fig. 3 Follow-up endoscopy 8 weeks after the first dose of infliximab revealed complete resolution of the intestinal lesions in: a the duodenum; and $\mathbf{b}$ the ileum.
C. K. Lee, J. Y. Park, J.-J. Shim, J. Y. Jang Division of Gastroenterology, Department of Internal medicine, School of Medicine, Kyung Hee University, Seoul, Korea

\section{References}

1 Kuroda T, Tanabe N, Harada $T$ et al. Longterm mortality outcome in patients with reactive amyloidosis associated with rheumatoid arthritis. Clin Rheumatol 2006; 25 : 498-505

2 Elkayam O, Hawkins PN, Lachmann $\mathrm{H}$ et al. Rapid and complete resolution of proteinuria due to renal amyloidosis in a patient with rheumatoid arthritis treated with infliximab. Arthritis Rheum 2002; 46: 2571 2573

3 Verschueren $P$, Lensen $F$, Lerut $E$ et al. Benefit of anti-TNFalpha treatment for nephrotic syndrome in a patient with juvenile inflammatory bowel disease associated spondyloarthropathy complicated with amyloidosis and glomerulonephritis. Ann Rheum Dis 2003; 62: 368-369

4 Ebert EC, Hagspiel KD. Gastrointestinal and hepatic manifestations of rheumatoid arthritis. Dig Dis Sci 2011; 56: 295-302
Bibliography

DOI $10.1055 / \mathrm{s}-0030-1256741$

Endoscopy 2011; 43: E326 - E327

(c) Georg Thieme Verlag KG Stuttgart · New York . ISSN 0013-726X

\section{Corresponding author}

\section{K. Lee, MD, PhD}

Department of Internal medicine School of Medicine

Kyung Hee University

1 Hoegi-dong, Dongdaemun-gu

Seoul, 130-702

Korea

Fax: 82-2-9681848

cklee92@paran.com 